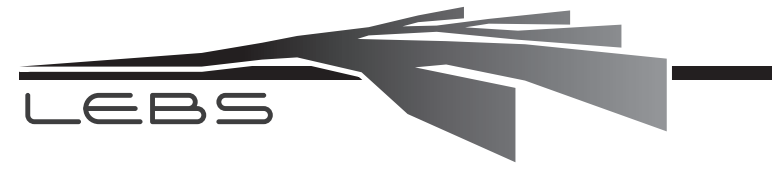

OPINION

\section{Is the Watching-Eye Effect a Fluke?}

\author{
Ryo Oda \\ Nagoya Institute of Technology, Nagoya 466-8555, Japan \\ "Author for correspondence (oda.ryo@nitech.ac.jp)
}

The watching-eye effect is a phenomenon wherein artificial surveillance cues enhance prosocial behavior toward strangers. Two meta-analyses on the effect, which focused on generosity measured by donations and economic games, suggest that artificial surveillance cues do not influence the donation amount. However, the factors possibly affecting the watching-eye effect should be examined more carefully. The most important factor that can bias results is the number of people around when the participants make a donation decision.

\section{Keywords}

watching-eye effect, meta-analysis, replication crisis

Replication crisis is currently a hot topic in behavioral sciences, including the watching-eye effect. The watchingeye effect is a phenomenon wherein artificial surveillance cues increase prosocial behavior toward strangers. Prosocial behavior includes many kinds of behaviors, such as generosity toward others, good manners and honesty. While some previous studies demonstrated that images of watching eyes prevented littering, lying and theft (e.g., Bateson, Robinson, Abayomi-Cole, Greenlees, O'Connor, \& Nettle, 2015; Nettle, Nott, \& Bateson, 2012; Oda, Kato, $\&$ Hiraishi, 2015), such outcomes are difficult to compare quantitatively. Therefore, two meta-analyses focused on generosity as measured by donations and economic games. One of these meta-analyses, conducted by Nettle, Harper, Kidson, Stone, Penton-Voak and Bateson (2013), included seven dictator game studies and reported that surveillance cues did not increase the mean amount of money donated by dictators, while the proportion of dictators who donated money was greater under the surveillance cue condition. The other analysis by Northover, Pedersen, Cohen and Andrews (2017) on amount given in 26 studies showed no effect of surveillance cues and that on proportion who gave any money in 27 studies revealed null effect either. These two meta-analyses suggest that artificial surveillance cues do not influence at least donation amounts.

However, potential factors affecting the watchingeye effect should be examined more carefully. The effect size of surveillance cues could be small, as the metaanalyses suggested, but this does not necessarily mean that the phenomenon is neither reproducible nor significant.
Although the dependent variable in both meta-analyses was restricted to generosity, the experiments employed a variety of methods. The most important factor to control is the number of people around when a donation is made. Oda and Ichihashi (2016) placed collection boxes with/ without stylized eyes in an izakaya (a Japanese-style tavern) and reported that the effect of the stylized eyes was more salient when fewer people were in the vicinity. Two previous studies using collection boxes also found that the watching-eye effect was stronger when fewer people were present (Ekström, 2012; Powell, Roberts, \& Nettle, 2012). Although the findings of another field study investigating norm compliance behavior were consistent with these studies (Ernest-Jones, Nettle, \& Bateson, 2011), there has been only these three studies investigating donation. However, if the number of people in the vicinity modulates the watching-eye effect, it is inappropriate to treat simultaneous classroom surveys (e.g., Rigdon, Ishii, Watabe, \& Kitayama, 2009) and online experiments (e.g., Raihani \& Bshary, 2012) as being the same as controlled laboratory experiments. Rigdon et al. (2009) used a paper and pencil classroom survey, and Raihani and Bshary (2012) measure behavior in the online labor market, MTurk, to investigate the watching-eye effect. Although it was not guaranteed that no real observers were in the vicinity of their participants, both studies were included in the meta-analyses of Nettle et al. (2013) and Northover et al. (2017). Moreover, Northover et al. (2017) also analyzed the results of Pfattheicher (2015), in which MTurk was again employed. Although it is uncertain what the effect of removing these studies would be on the findings of the meta-analyses, the results could have been biased by the inclusion of several studies that did not control the environment in which participants were making decisions.

Why does the watching-eye effect diminish when other people are in the vicinity? One possibility is that a bystander-type effect weakens the motivation for making a donation (Latané \& Darley, 1970). For example, according to Oda and Ichihashi (2016), a restaurant customer might expect other customers to make a donation, which could weaken their own motivation to do so. Another possibility is that when the restaurant is crowded, the collection box might be difficult to see, or customers may be distracted by the noisy atmosphere, thus not attending to the box. However, in that study, the donation amount correlated positively with the number of customers and did not decrease as the number of customers increased (see Figure 2 of Oda \& Ichihashi, 2016). Another plausible possibility is that the positive effect on pro-sociality may decline when patrons become habituated to being watched by "real" eyes. Sparks and Barclay (2013) reported that the watching-eye effect emerged reliably only after short exposures to eye images, both in their original experiment and according to a meta-analysis. This could be due to a decrease in responsiveness to an eye stimulus presented for a prolonged period. If such habituation occurs with 
prolonged exposure to eye stimuli, it would also likely with prolonged exposure to the eyes of actual people. Unfortunately, few field studies have examined the effects of the number of people in the vicinity when a donation decision is made (Ekström, 2012; Powell et al., 2012). In addition to field studies, experimentally controlled studies are needed to compare the effects of real and stimulus eyes.

Subsequent to the meta-analysis by Northover et al. (2017), further studies on the watching-eye effect have been published. Manesi, Van Lange and Pollet (2016) investigated the effects of eyes on allocation of workload (completing a dull cognitive task) to others in a laboratory setting. They compared the effects of images of watching and non-watching eyes and reported that participants showed more prosocial workload allocation when exposed to a pair of watching versus closed eyes. Two laboratory experiments were carried out by Kawamura and Kusumi (2017), who measured donation amounts in dictator games, and manipulated prosocial norms by informing the participants that either a high or low mean donation amount was given by previous participants. Although they found that watching eyes promoted donations only when the purported norm in the first experiment was prosocial, in the second experiment the same watching eyes did not promote generosity regardless of the norm. Thus, the study suggested that a prosocial norm can modulate the watching-eye effect. None of three online experiments found any positive effect of watching eyes on prosocial behavior (Manesi, Van Lange, Van Doesum, \& Pollet, 2018; Raihani \& Bshary, 2017; Saunders, Taylor, \& Atkinson, 2016). Saunders et al. (2016) asked participants to donate to UNICEF via MTurk. Similarly, Raihani \& Bshary (2017) measured the amount given via MTurk in dictator games. Manesi et al. (2018) evaluated participant donations to typhoon victims via CrowdFlower. Four field experiments have also been reported. Manesi and Pollet (2017) measured generosity using the "lost letter" paradigm, while Koornneef, Dariel, Elbarazi, Alsuwaidi, Robben and Nikiforakis (2018) examined the watchingeye effect with respect to normative behavior, through observing hand-washing by advanced undergraduate students of a Doctor of Medicine program. The other two field experiments focused on donations made to collection boxes, on a university campus and in a museum, respectively (Kelsey, Vanish, \& Grossmann, 2018; Lennon, Grant, \& Montrose, 2017). Lennon et al. (2017) reported a negative effect of watching eyes on prosocial behavior, while Kelsey et al. (2018) reported a positive effect. However, neither of these studies considered the effect of the number of people in the vicinity. Although metaanalysis is a powerful method to examine the robustness of an effect, in this case the results cannot completely rule out the watching-eyes effect. Further meta-analyses of the watching-eye effect are needed.

\section{References}

Bateson, M., Robinson, R., Abayomi-Cole, T., Greenlees, J., O'Connor, A., \& Nettle, D. (2015). Watching eyes on potential litter can reduce littering: Evidence from two field experiments. PeerJ, 3, e1443. (doi: 10.7717/ peerj.1443)
Ekström, M. (2012). Do watching eyes affect charitable giving? Evidence from a field experiment. Experimental Economics, 15, 530-546. (doi: 10.1007/ s10683-011-9312-6)

Ernest-Jones, M., Nettle, D., \& Bateson, M. (2011). Effects of eye images on everyday cooperative behavior: A field experiment. Evolution and Human Behavior, 32, 172-178. (doi: 10.1016/j.evolhumbehav.2010.10.006)

Kawamura, Y., \& Kusumi, T. (2017). The norm-dependent effect of watching eyes on donation. Evolution and Human Behavior, 38, 659-666. (doi: 10.1016/ j.evolhumbehav.2017.05.003)

Kelsey, C., Vanish, A., \& Grossmann, T. (2018). Eyes, more than other facial features, enhance real-world donation behavior. Human Nature, 29, 390-401. (doi: 10.1007/s12110-018-9327-1)

Koornneef, E. J., Dariel, A., Elbarazi, I., Alsuwaidi, A. R., Robben, P. B. M., \& Nikiforakis, N. (2018). Surveillance cues do not enhance altruistic behavior among anonymous strangers in the field. PLoS ONE 13: e0197959. (doi: 10.1371/journal.pone.0197959)

Latané, B., \& Darley, J. M. (1970). The unresponsive bystander: Why doesn't he help? Englewood Cliffs, NJ: Prentice-Hall

Lennon, P., Grant, R., \& Montrose, V. T. (2017). Stylized and photographic eye images do not increase charitable donations in a field experiment. Letters on Evolutionary Behavioral Science, 8, 28-31. (doi: 10.5178/lebs.2017.60)

Manesi, Z., \& Pollet, T. V. (2017). No support for the watching eyes effect across three "lost letter" field experiments. Letters on Evolutionary Behavioral Science, 8, 12-15. (doi: 10.5178/lebs.2017.56)

Manesi, Z., Van Lange, P. A. M., \& Pollet, T. V. (2016). Eyes wide open: Only eyes that pay attention promote prosocial behavior. Evolutionary Psychology, 14. (doi: 10.1177/1474704916640780)

Manesi, Z., Van Lange, P. A. M., Van Doesum, N. J., \& Pollet, T. V. (2018). What are the most powerful predictors of charitable giving to victims of typhoon Haiyan: Prosocial traits, socio-demographic variables, or eye cues? Personality and Individual Differences, 146, 217-225. (doi: 10.1016/j.paid.2018.03.024)

Nettle, D., Harper, Z., Kidson, A., Stone, R., PentonVoak, I. S., \& Bateson, M. (2013). The watching eyes effect in the Dictator Game: It's not how much you give, it's being seen to give something. Evolution and Human Behavior, 34, 35-40. (doi: 10.1016/ j.evolhumbehav.2012.08.004)

Nettle, D., Nott, K., \& Bateson, M. (2012). 'Cycle thieves, we are watching you': Impact of a simple signage intervention against bicycle theft. PLoS ONE, 7, e51738. (doi: 10.1371/journal.pone.0051738)

Northover, S. B., Pedersen, W. C., Cohen, A. B., \& Andrews, P. W. (2017). Artificial surveillance cues do not increase generosity: Two meta-analyses. Evolution and Human Behavior, 38, 144-153. (doi: 10.1016/ j.evolhumbehav.2016.07.001)

Oda, R., \& Ichihashi, R. (2016). The watching eyes effect on charitable donation is boosted by fewer people in the vicinity. Letters on Evolutionary Behavioral Science, 7, 9-12. (doi: 10.5178/lebs.2016.52)

Oda, R., Kato, Y., \& Hiraishi, K. (2015). The watching-eye effect on prosocial lying. Evolutionary Psychology, 13. (doi: 10.1177/1474704915594959)

Pfattheicher, S. (2015). A regulatory focus perspective on reputational concerns: The impact of prevention- 
focused self-regulation. Motivation and Emotion, 39, 932-942. (doi: 10.1007/s11031-015-9501-2)

Powell, K. L., Roberts, G., \& Nettle, D. (2012). Eye images increase charitable donations: Evidence from an opportunistic field experiment in a supermarket. Ethology, 118, 1096-1101. (doi: 10.1111/eth.12011)

Raihani, N. J., \& Bshary, R. (2012). A positive effect of flowers rather than eye images in a large-scale, crosscultural dictator game. Proceedings of the Royal Society B: Biological Sciences, 279, 3556-3564. (doi: 10.1098/rspb.2012.0758)

Raihani, N., \& Bshary, R. (2017, October 2). Eye images do not promote prosocial behaviour or norm compliance in an online Dictator Game. PsyArXiv. (doi: 10.31234/ osf.io/7a8ft)

Rigdon, M., Ishii, K., Watabe, M., \& Kitayama, S. (2009). Minimal social cues in the dictator game. Journal of Economic Psychology, 30, 358-367. (doi: 10.1016/ j.joep.2009.02.002)

Saunders, T. J., Taylor, A. H., \& Atkinson, Q. D. (2016). No evidence that a range of artificial monitoring cues influence online donations to charity in an MTurk sample. Royal Society Open Science, 3: 150710. (doi: 10.1098/rsos.150710)

Sparks, A., \& Barclay, P. (2013). Eye images increase generosity, but not for long: The limited effect of a false cue. Evolution and Human Behavior, 34, 317322. (doi: 10.1016/j.evolhumbehav.2013.05.001) 